\title{
Measuring Information System Project Success through a Software-Assisted Qualitative Content Analysis
}

Jin Xiu Guo

\section{ABSTRACT}

Information System (IS)/IT project success is a growing interest in management due to its high impact on organizational change and effectiveness. Libraries have been adopting integrated library systems (ILS) to manage services and resources for years. It is essential for librarians to understand the mechanism of IS project management in order to successfully bring technology innovation to the organization. This study develops a theoretical model of measuring IS project success and tests it in an ILS merger project through a software-assisted qualitative content analysis. The model addresses project success through three constructs: (1) project management process, (2) project outcomes, and (3) contextual factors. The results indicate project management success alone cannot guarantee project success; project outputs and contextual factors also influence success through the leadership of the project manager throughout the lifecycle. The study not only confirms the proposed model in a post-project evaluation, but also signifies that project assessment can reinforce organizational learning, increase the chance of achieving success, and maximize overall returns for an organization. The qualitative content analysis with NVivo 11 has provided a new research method for project managers to self-assess an IS/IT project success systematically and learn from their experiences throughout the project lifecycle.

\section{INTRODUCTION}

Information Technology (IT) project success has drawn more attention in the last two decades due to its high impact on organizational change. More companies have conducted their innovation to gain business advantages through IS projects. In the United Kingdom alone, 21 percent of the gross value increased in manufacturing and construction happens through complex products and IS development projects. However, the implementation of IS projects has not been successful as practitioners hoped. Nicholas and Hidding reported that only 35 percent of IT projects were completed on time and budget, and met the project requirements. ${ }^{1}$ The U.S. Office of Electronic Government and Information Technology (OEGIT) noted that only 25 percent of 1,400 projects reached the office's goals and more than $\$ 21$ billion spent on IT projects were in jeopardy. ${ }^{2}$ In the European Union, about 20 to 30 percent of contracted IT/IS projects could not meet the stakeholders' expectations and cause the loss of $€ 70$ billion or $\$ 99$ billion. ${ }^{3}$ Although some IT projects are considered successful from the perspective of project management, project sponsors hardly recognize the results leading to organizational effectiveness. It is critical for IT practitioners to explore new methods to articulate what IT project success is and then improve project performance.

Jin Xiu Guo (jin.x.guo@stonybrook.edu) is Director of Collections and Resource Management, Frank Melville, Jr. Memorial Library, Stony Brook University 
Traditionally, the measurement of IT project success focuses on internal measures such as project time, cost, risk, and quality, which address project efficiency. In recent years, external measures, such as product satisfaction and organizational effectiveness, have gained more attention.

Moreover, contextual factors such as top management support, project managers' qualifications, system vendors, implementation consultants, and adaptation to change have shown critical effects on project success. The lack of literature in the post-project evaluation and merger of multiple information systems (IS) still exists. Notably, the consolidation of information systems of different organizations creates additional challenges for the new organizations. Diverse cultures and leadership styles may create barriers for managers to gain the trust of employees who used to work at a different institution. Nevertheless, the adaptation to change for all staff is necessary in the course of the merger. The need for addressing the impact of these factors on IS project success is increasing.

Libraries have adopted the ILS to manage services and resources for the last two decades. The next generation system-cloud-based Library Management Systems-are now replacing existing ILS. To improve the efficiency of higher education, consolidation of public universities or colleges is still a viable alternative. It is essential for librarians to understand the mechanism of IS project management in order to successfully bring technology innovation to the organization.

This study is to fill the gap by examining IS project success factors and developing a model to measure IS project success. The model can help practitioners better understand IS project success and improve the chance of success. The author firstly provides a historical account of the definitions of project success and measures adopted. What follows is to apply the model in a postproject evaluation at an academic library.

\section{THEORETICAL BACKGROUND}

Researchers and practitioners have been seeking IT project success through both quantitative and qualitative studies to find out what makes a successful IT project and how a project manager can make better decisions to increase the chance of project success. This review is to examine how project success is defined and what criteria practitioners employ for measurement.

IT projects can be at different levels of complexity. For instance, a project of enterprise resource planning (ERP) implementation is more complicated and requires more resources to deploy across organizational functions. This type of projects might quickly overrun budget and deadline. As a result, the studies on ERP implementation success draw more attention. Cảrstea believes that project success is to achieve the targets that an organization has created and can be relatively measured against time, cost, quality, final results obtained, resources, the degree of automation, and international standards with a flexible evaluation system. He suggests that project managers may analyze the goal discrepancies between the current and new to self-evaluate the progress. ${ }^{4}$ Although this method emphasizes project efficiency, the self-developed evaluation system has shown the potential for IT project managers to control planning and organization of multiple IT projects within the organization.

Instead of studying project management process alone, Tsai et al. incorporate system providers, implementation consultants, and the achievement level of project management into DeLone and McLean's modified IS success model. They describe the ERP project success as efficient deployment and enhancement of organizational effectiveness. The success indicators include the 
accomplishment level of project management and the degree of the improvement of IS performance. The metrics of project management are fulfilling business implementation goal, top management support, budget, time, communication, and troubleshooting; while the system performance dimensions include achieving integration of systems for system quality, information quality, system use, user satisfaction, individual and organizational impacts. The authors applied the research model to a quantitative study to test five hypotheses with SERVQUAL (service quality) instruments. The results show that the services provided by system vendors and implementation consultants are correlated with project management, then from project management to system performance. ${ }^{5}$ It is worth mentioning that this measurement integrates project management into the IS success model and confirms the contribution of project management to ERP performance that leads to the improvement of organizational effectiveness. Both studies indicate IS project measures should comprise the dimensions of project management success and business goals.

With the similar interest of ERP, Young and Jordan investigate the impact of top management support (TMS) on ERP implementation success through descriptive case studies. The authors regard project success as the delivery of "expected benefits" and the achievement of "above average performance." The findings of the research reveal that TMS is the most important critical success factor (CSF) that affects IT project success through the involvement of top management in project planning, result follow-ups, and the facilitation of management problems, but project management success does not guarantee project success resulting in organizational productiveness. $^{6}$

Researchers are also interested in different perspectives of IT project success. Irani believes IS project appraisal should incorporate investment evaluation into the project lifecycle. A project manager evaluates IS impacts before, during, and after the investment is secured to dynamically justify the investment and ensure the project is in alignment with the organizational strategy. The author also points out that post-project evaluation lacks in current project management so that organizations lose a great learning opportunity to optimize their project management. ${ }^{7}$

Furthermore, Peslak inspects the relationship between IT project success and overall IT returns from the viewpoint of financial executives. The author defines IT project success as organizational success in which staying abreast of technology and the ability to measure project and balance managerial control over projects positively affect IT project success, then project success to overall IT returns. ${ }^{8}$

Likewise, Lacerda and Ensslin develop a conceptual model from the standpoint of external consultants to assess software projects. The theoretical framework contains the hierarchical structure of value, analysis, and recommendation, where they identify performance descriptors and analyze project values to improve the decision process in the course of the consultation. ${ }^{9}$ Nicholas and Hidding discover business goals, time for learning and reflection, and flexibility of the product are associated with project success through a series of interviews with IT project managers. ${ }^{10}$

Additionally, researchers make efforts to explain project outcomes for better understanding project success. Thomas and Fernández believe project success is changeable to each company, but the success criteria should consist of project management, technical system, and business goals that underscore business continuity, met business objectives, and delivery of benefits. ${ }^{11}$ INFORMATION TECHNOLOGY AND LIBRARIES | MARCH 2019 
Another study performed by Kutsch also proves that the achievement of business purpose; benefit to the owner; the satisfaction of owners, users, and stakeholders; achieving prestated objectives; quality; cost and time; and satisfaction of team are sequentially significant variables affecting project outcomes. ${ }^{12}$ The study further attests that organizational effectiveness is an essential criterion of IT project success.

Interestingly, researchers also examine individual success indicators such as quality and risk to deepen their understanding of project success. Geraldi, Kutsch, and Turner think project quality has eight attributes including (1) a commitment to quality, (2) enabling capabilities, (3) completeness, (4) clarity, (5) integration, (6) adaptability, and (7) compliance along with (8) value-adding and met requirements. ${ }^{13}$ Among them, enabling capabilities and adaptability are comparatively new. This discovery discloses that project quality is evaluated vigorously in the project lifecycle, which is consistent with Cảrstea's finding that project managers need to assess the projects regularly to recognize project controls and safety to achieve project goals. Such practices create the agility for software development projects and secure the resources needed for development.

\section{Summary of Literature}

The literature review indicates that it is necessary to define project performance criteria and outcomes to measure IS project success. IS project success is the achievement of project management process and project goals. When measuring an IS project, practitioners should also consider the impacts of contextual factors throughout the project lifecycle. System vendors, consultants' services, management support, communication, adaptation to changes, time for learning and reflection, product flexibility, and project complexity are environmental influences. It is essential for practitioners to create an opportunity for organizational learning and improve future project success through a post-project evaluation.

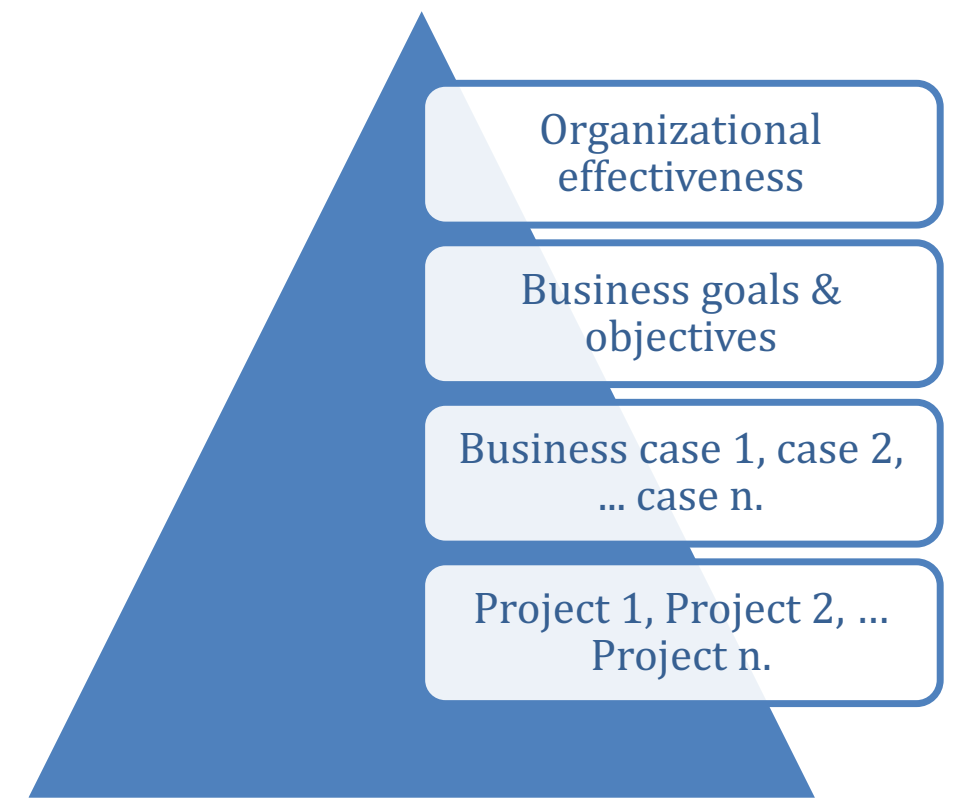

Figure 1. The relationship between Project Success and Organizational Effectiveness. 


\section{PROJECT SUCCESS MODEL}

The purpose of this study is to develop the measurement of IS project success based on the findings of the literature review. Therefore, the first step is to define project success. Project success comprises project management success and the achievement of business goals. In the previous studies, practitioners emphasized project management success but pay less attention to project outcomes, which leads to many unexplainable project failures. For example, some IT projects did not meet the business goals but conformed to the criteria of project management success. It might be a successful project from the perspective of project management process although it failed to attain the project goals. The relationship between IS projects and organizational effectiveness is described in figure 1. Each IS project makes at least one business case, and each business case contributes to at least a business objective. It will be a successful IS project if the project outcomes reach the business goals resulting in organizational effectiveness.

The purpose of project performance criteria is to measure project progress throughout its lifecycle. Without standards, a project manager could lose the control over the project, and most likely fail. As a result, the next step is to identify the measures of project success. The indicators of project management success have been widely studied and tested. The project scope, time, cost, quality, and risk are on the top of the metrics list. The discovery of literature review shows researchers employ business continuity, achieving business objectives, delivery of benefits, and the perceived value of a project to measure project outcomes. It is noteworthy that contextual factors also impact project success, influences such as top management support (TMS), user involvement, system vendors, project manager's qualifications, communication, and the complexity of a project, and adaptation to change need to be measured as well. Hence, the author proposes a measurement model as shown in figure 2 . 


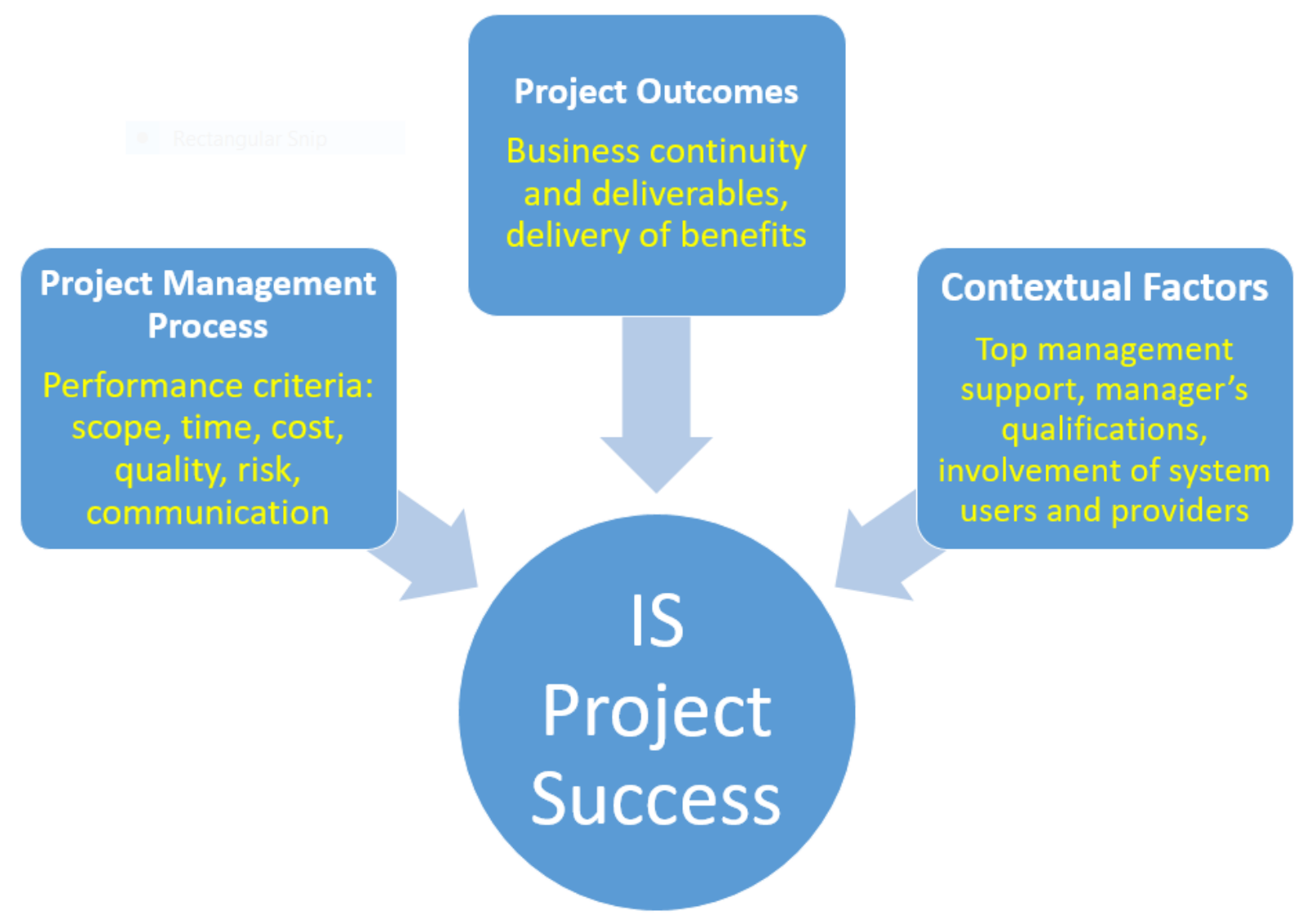

Figure 2. Model for Measuring IS Project Success.

Three constructs effect IS project success in this model. Project management process is a tool to help a project manager attain success, where project performance criteria are identified to control quality and assess the progress throughout the lifecycle. On the other hand, project outcomes entail project goals to ensure ultimate project success. The contextual factors may contribute to success directly or indirectly by influencing project management process or organizational environment such as change management. Therefore, a project manager has to examine three constructs when assessing project success. To demonstrate the application of the model, the author conducted a case study on an ILS merger project.

\section{CASE STUDY: A POST-PROJECT EVALUATION}

\section{Background}

In November 2013, the Board of Regents of the University System of Georgia announced the consolidation of Kennesaw State University (KSU) and Southern Polytechnic State University (SPSU). The merger of two state university libraries was one of the main tasks and involved merging two integrated library systems (ILS). The project involved removing duplicate bibliographic and customer records between two libraries and of relational databases that contain financial, bibliographic, transactional, vendor, and customer data. The ILS provider, Ex Libris, and two university libraries executed the merger with the support of GALILEO Interconnected Libraries (GIL) IT staff. The ILS merger implementation team comprised of two IT experts from Ex 
Libris and fourteen ILS users from two libraries across five functional units comprising acquisition, cataloging, circulation and interlibrary loan, serials, and system administration. KSU/SPSU and Ex Libris had a project manager on each side, and the author was the KSU/SPSU project manager. The GIL Support team facilitated the implementation of the merger. The project goal was to operate two libraries with a consolidated ILS by July 2015 without interrupting services to students, staff, and faculty. The project was completed within eighty-one days and the consolidated university libraries were operated uniformly by the timeline. The team also won the 2015 Georgia Library Association Team Award due to its success.

\section{Methodology}

The methodologies adopted in previous researches include interview and survey. Both methods need to collect feedback from stakeholders during the post-project period, which sometimes can be challenging to reach the project stakeholders once the project is completed. However, many written communications including project documentation, emails, and reports are invaluable data for project managers to assess project success. Researchers have utilized software to assist content analysis in qualitative studies.

Hoover and Koerber used NVivo to analyze data like text, interview transcripts, photographs, audio and video recordings by coding and retrieving to understand sophisticated relations among those data. ${ }^{14}$ Researchers think that computer-assisted qualitative data analysis (CAQDAS) has created new research practices and helped data analysis, research management, and theory development, where CAQDAS becomes a synonym of qualitative research. ${ }^{15}$ Balan's team manually coded and categorized the dimensions identified in concept analysis, then employed concept mapping to present data relationship, which is an integration of qualitative and quantitative methods. ${ }^{16}$ The word tag cloud in NVivo is a technique to assess the relevance of the data obtained or gathered to the research topic and treemap on the other hand is a tool to extract the new themes along with their relationship from the study data. ${ }^{17}$ Hutchison et al. believed that CAQDAS could facilitate the ground theory investigation. The group utilized the memo in NVivo to monitor emerging trends and justify the research purpose and theoretical sampling procedures. They also experienced the model-building tool to visualize the analytical observations. ${ }^{18} \mathrm{~A}$ study on content analysis of new articles indicated NVivo could assist qualitative research through data organization, idea management, querying data, and modeling. The research group also raised the concern about analytical reliability because qualitative data analysis is a highly interpretive method. Therefore, they suggested utilizing double coding and comparison of codes by different researchers to resolve this problem. ${ }^{19}$ Paulus's team suggested researchers should write a description of the software to allow audience unfamiliar with the tool to not only appreciate its role in the study, but also understand how precisely the software enhances the potential in their analyses. $^{20}$

In this case study, the author adopted NVivo 11 to conduct a content analysis to testify the proposed model by measuring IS project success, which is a qualitative method for practitioners to assess project with textual data in the post-project period.

\section{Data Collection}

The data gathered in this study include the email communications between the project manager and stakeholders, the reports of University Consolidation Operational Work Group (OWG), and project committee reports. After reviewing all document data to ensure the relevancy to the 
research topic, the author imported 878 emails, twenty-five OWG reports, and sixty-three project committee reports into NVivo 11.

\section{Content Analysis Process}

The Software-NVivo 11. NVivo 11 is the software package that allows researchers to collaborate and conduct qualitative studies. Researchers can import various types of raw data including social media into NVivo 11 to store, manage, and share the data throughout the research process. However, initial learning and mastering the software could pose a difficult hurdle for researchers to perform a software-assisted qualitative research.

Data Preparation and Import. NVivo 11 can process documents (MS Word, PDF, or RTF), survey, audio, video, and image. Researchers may import Outlook emails saved as .msg files into NVivo 11 directly. It is also noted that emails imported into NVivo become PDFs and any supported attachments are imported as well. In this study, the OWG and committee reports in either MS Word or PDF were imported to NVivo directly. To ensure the email content relevant to the project, the author opened the software NVivo 11 and emails in Outlook 2010 simultaneously, and then dragged each email into the Sources List View of NVivo 11 (see figure 3) after reviewing each email.

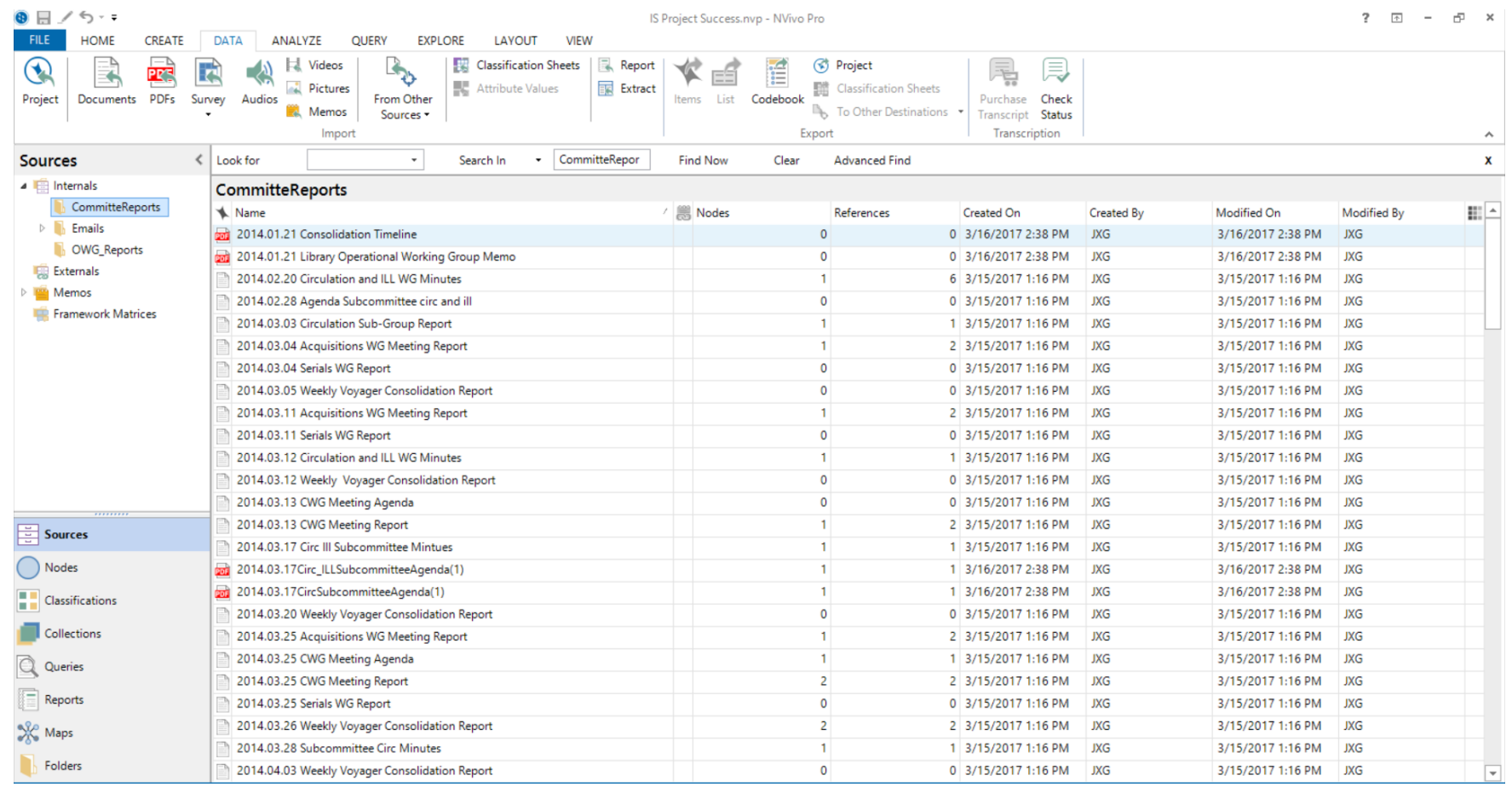

Figure 3. Sources List View in NVivo 11.

Coding. Coding is a way of categorizing all references to a specific topic, theme, person, or other entity. The process of coding can help researchers to identify patterns and theories in research data. ${ }^{21}$ In this study, the author adopted coding using queries to answer the following research questions:

- What is IS project success?

- What are the factors that affect IS project success? 
- How do these factors influence IS project success?

Below are the steps of coding source data:

- Run the query of word frequency in all data sets using the criteria of one hundred most frequent words with minimal five-character length including exact matches, stemmed words, and synonyms.

- Review the word list, remove irrelevant words from the list, and re-run the query until the words are accurate and relevant to the research topic.

- Create the parent nodes (e.g. contextual factors, project management process, project outcomes) and child nodes (e.g. top management support, manager's qualifications, project involvement) based on the proposed model, and then save the results of word frequency in respective nodes (see the coding in figure 4).

- Run the query of word frequency with the same criteria in the context nodes (within each parent node)

- Review the results of word frequency and save the new word as a new node.

- Review all node references and sources, merge relevant nodes, and remove irrelevant ones as needed.

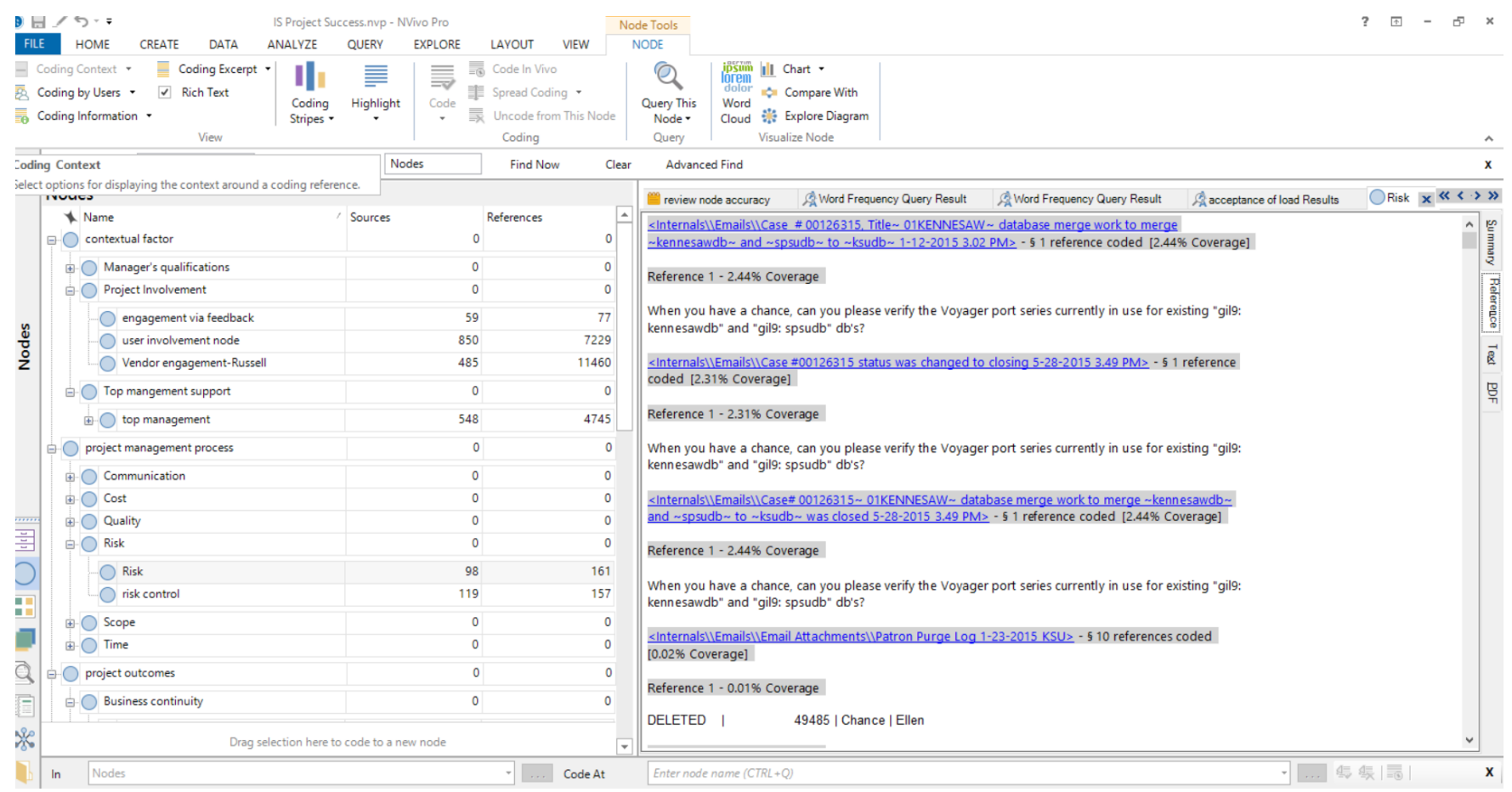

Figure 4. Coding Using Queries.

\section{FINDINGS AND DISCUSSION}

\section{An Overview of Content Analysis}

Previous studies have shown that visualization tools such as models, charts, and treemaps provided by NVivo can be helpful to present the findings of qualitative studies. ${ }^{22}$ Therefore, the author used the model tool to gain a better understanding and overview of key themes in the ILS merger project. Since the number of emails is much larger than the number of reports, the author 
decided to display the themes of emails and reports separately. Figures 5 and 6 are the word treemaps for the emails and reports respectively.

email without attachment

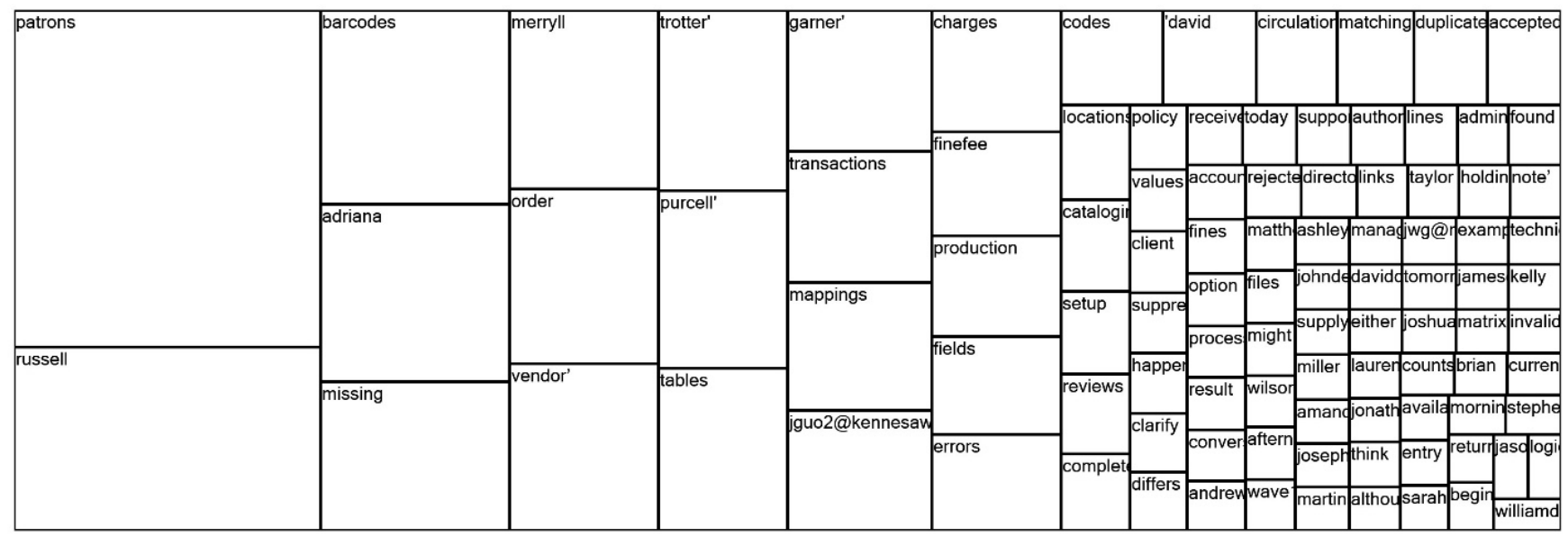

Figure 5. Email Tree Map.

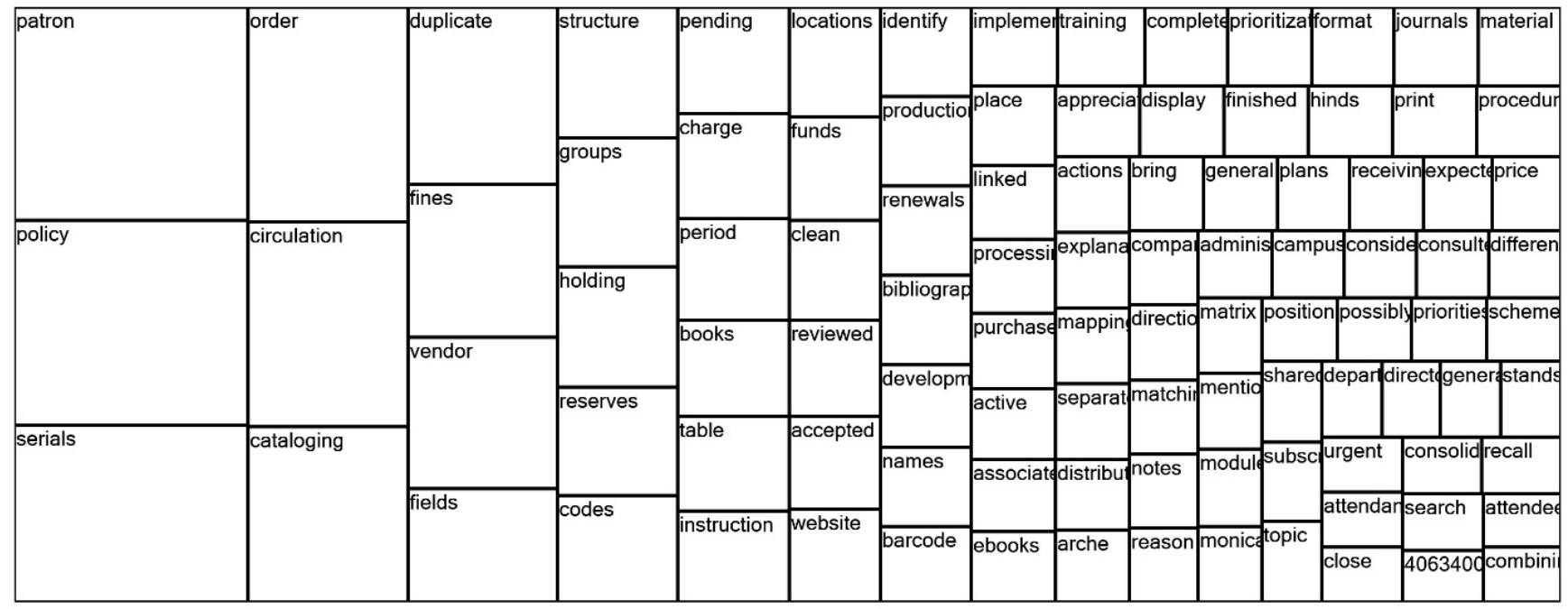

Figure 6. Report Tree Map.

The treemap is the visualization of the results of word frequency queries. In figure 5, the concepts of patron, barcode, missing, fines, charge, circulation, and policy are library user transactional data; while order, vendor, complete, Wilson, lines, Taylor, and holding show procurement information. The themes of production, mapping, duplicate, matching, location, cataloging, and process stand for library resource data. Hence, the acquisition, bibliographic, patron, and transactional data are the primary content migrated to the new ILS. The names mentioned such as Russell, Adriana Meryll, Trotter, and David reveal the involvement of system and service providers and top management. 
Figure 6 displays more details on library resource data such as serials, codes, bibliographic, ebook, format, journal and print. The user transactional data also appear. The subjects of production, implement, identify, training, mapping, match, finish, matrix, plan, procedure, campus and urgent indicate project management process. The term "accepted" in contrast shows one of the project outcomes.

The treemaps shown above demonstrate that project management process, the involvement of user and system providers, top management, and project outcomes are the representatives of project success, which implies project success is to succeed in project management process, project outcomes, and engaging top management and system users and providers. How do these factors come together to impact project success? The next step is to examine the relationships among these variables and their interactions.

\section{Relationships among Constructs}

To analyze the concepts of contextual factors, project management process, and project outcomes further, the author utilized the model tool to create project maps. Project maps are graphic representations of the data in a project, which helps illustrate the relationships among constructs and answer the research questions of this study. The author further inspected each construct node by creating project maps.

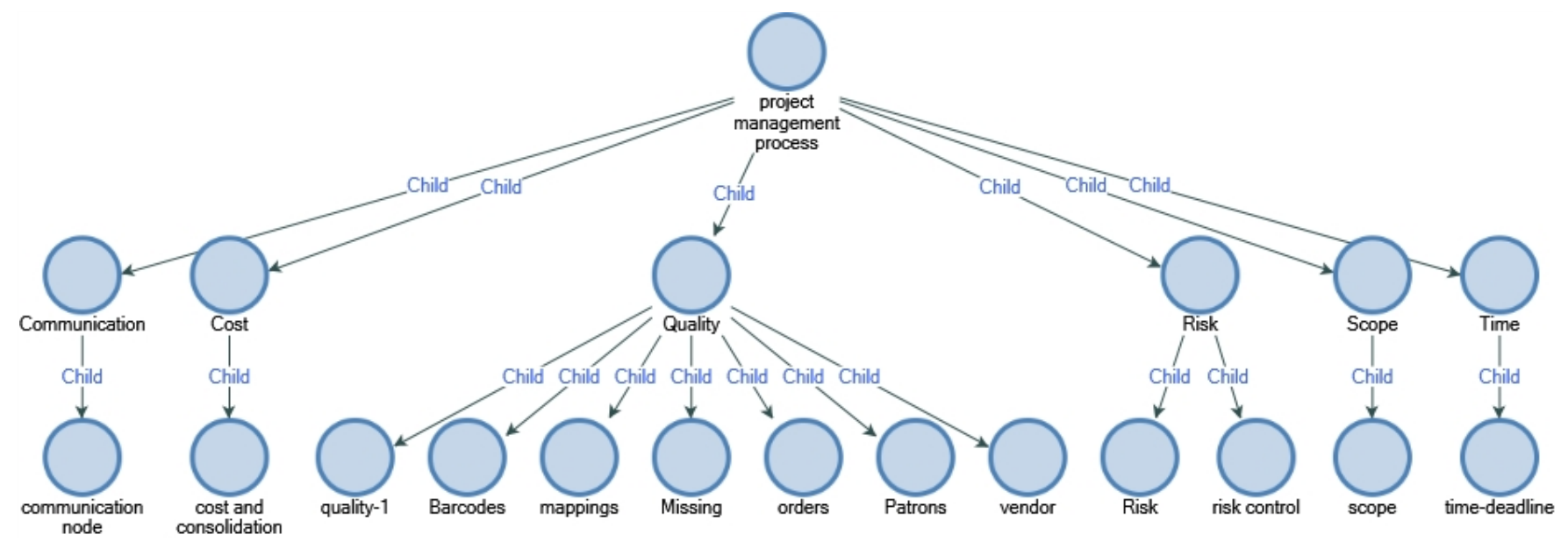

Figure 7. Project Management Process Map.

Figure 7 shows the relationships among the variables that affect the project management process. The child nodes of communication, project cost, quality, risk, time, and scope are the influencers of project management process. Their respective child nodes such as barcodes, missing, and deadline are the results of coding source data and well support how the concepts of communication, cost, quality, risk, scope, and time effect project management process correspondently. 


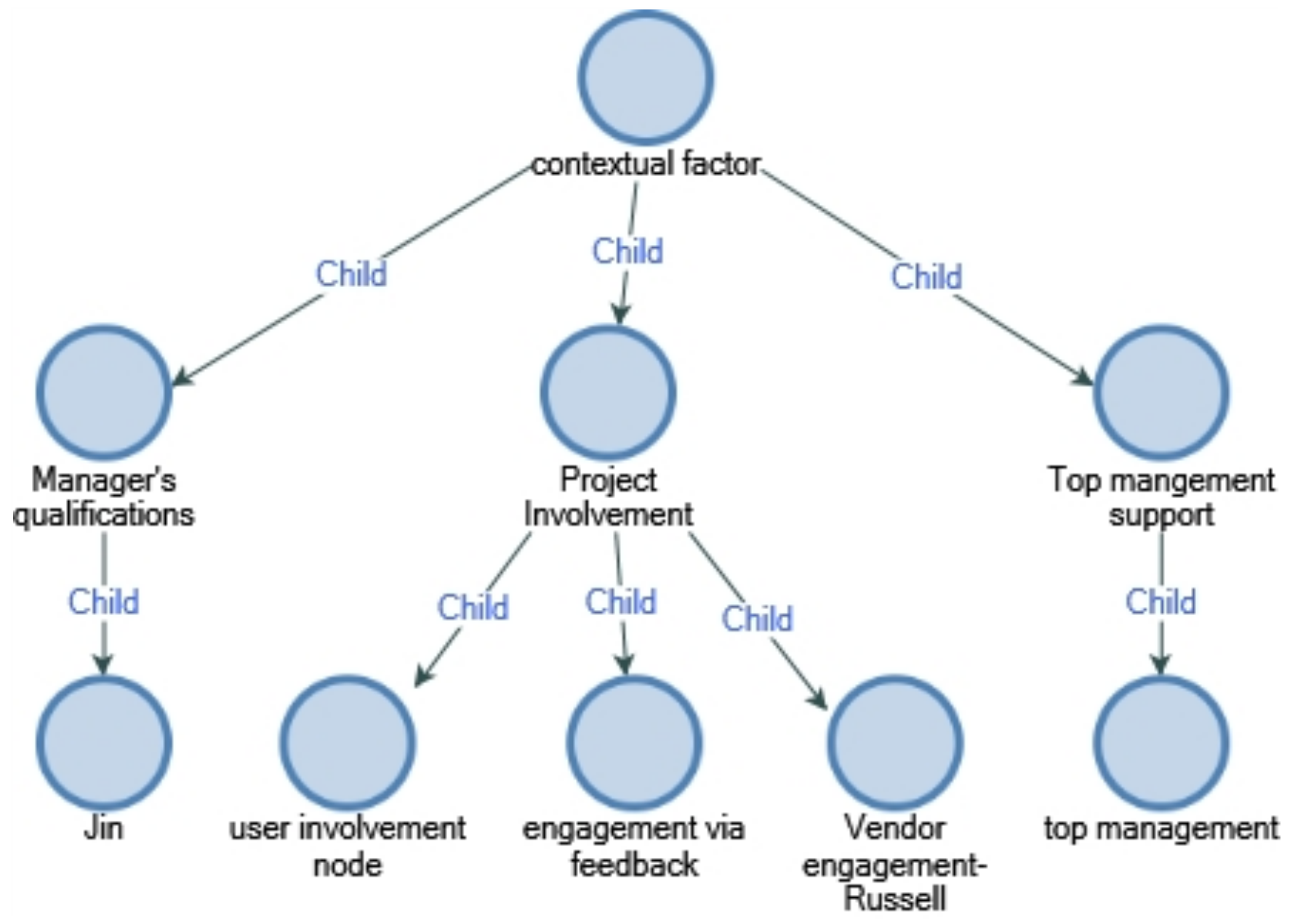

Figure 8. Contextual Factor Map.

Contextual factors have not been thoroughly discussed in previous project management practices. Figure 8 illustrates the results of coding source data within this construct. The engagement of users and vendors, and their feedback signify the variable of project involvement. The node of top management also confirms its parent node of top management support. Furthermore, Jin as the project manager is associated with the node of project manger's qualifications. She could affect project success either directly or indirectly through contextual factors. 


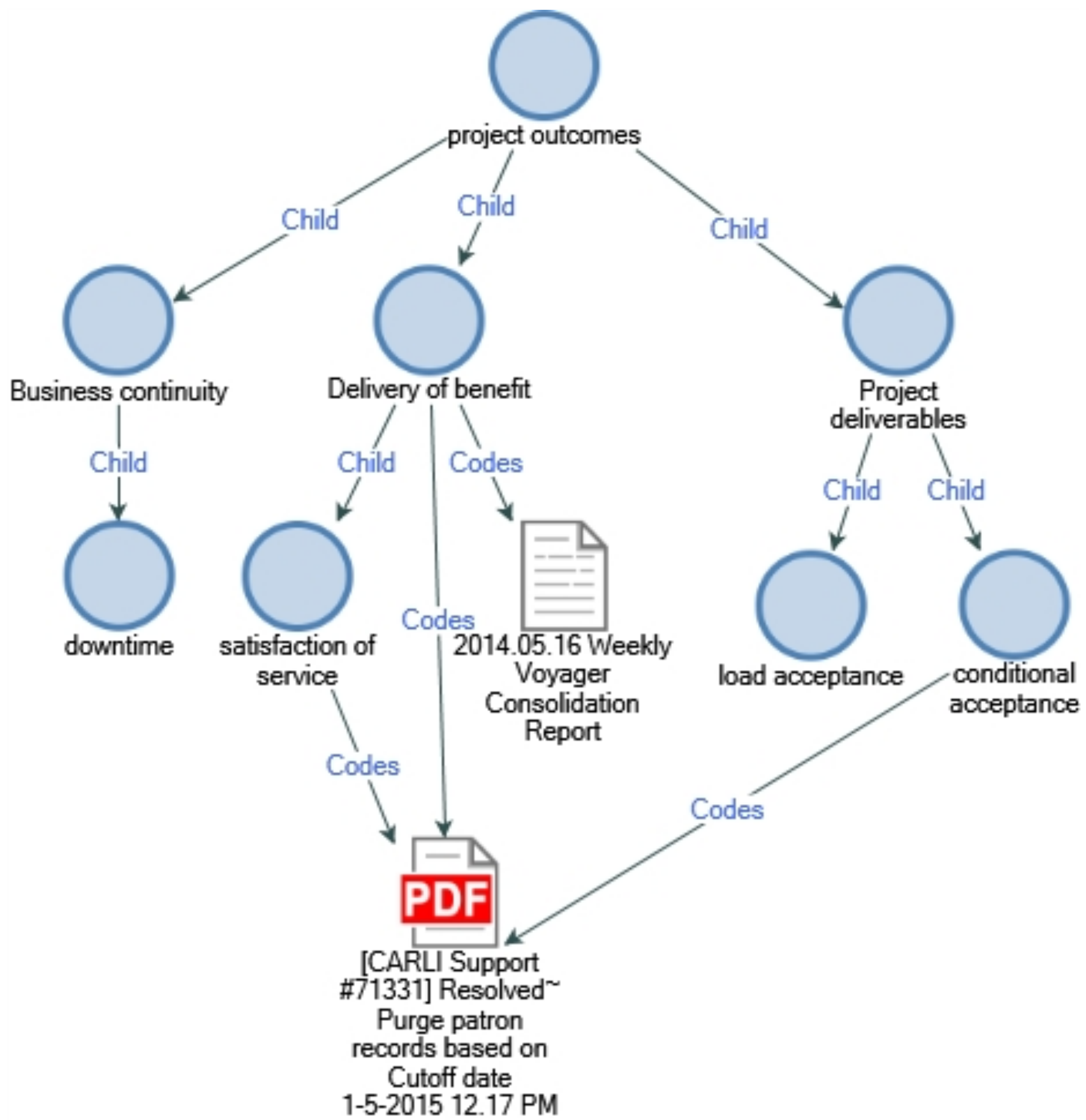

Figure 9. Project Outcomes Map.

Figure 9 represents the themes-downtime, service satisfaction, and acceptance are the child nodes of business continuity, delivery of benefit, and project deliverables correspondently. The PDF reference source supports the subjects of "satisfaction of service" and "conditional acceptance" as the child nodes of "delivery of benefits" and "project deliverables" respectively. Thus, business continuity, delivery of benefits, and project deliverables are the core factors to be considered when assessing project outcomes. Figures 7, 8, and 9 have demonstrated that the project would not be successful if the project management process was not executed appropriately, context factors INFORMATION TECHNOLOGY AND LIBRARIES | MARCH 2019

(c) (i) 
were not fully met, or preferred project outcomes were not delivered. In other words, if one of three above project variables is not executed or delivered appropriately, the project could fail.

\section{The Role of Project Manager}

Although figures 7, 8, and 9 have signified the three constructs can affect project success, but do not tell how project management process, project outcomes, and contextual factors play together in this role. Consequently, the author hoped to identify the connections between project items and to see if there are gaps or isolated items unexplained by the proposed model. To create such project map in NVivo 11, the author chose emails as project items and added the issues associated with the project manager Jin to the map.

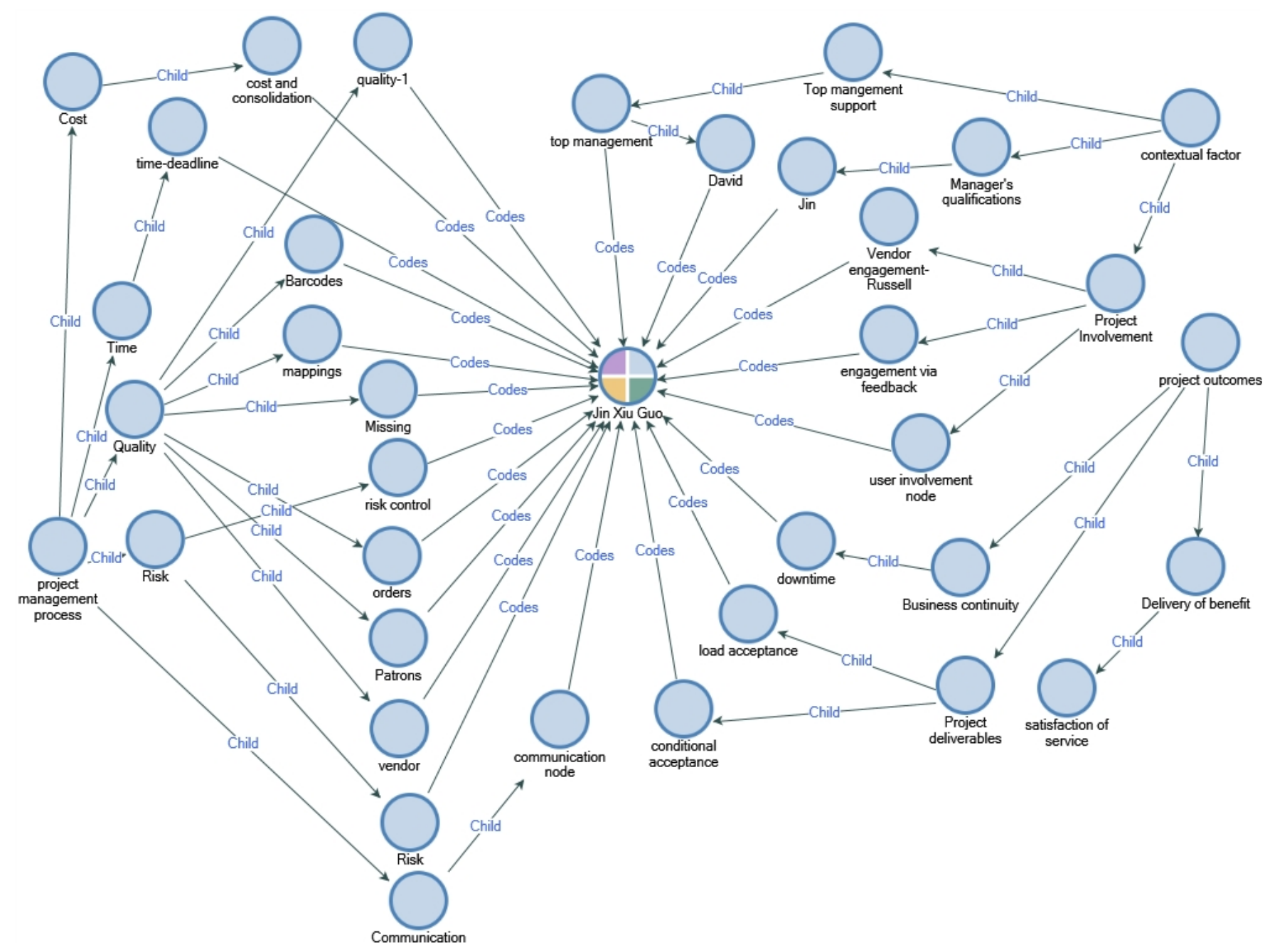

Figure 10. Manager's Project Map.

This case study is to test the proposed model in a post-project assessment. The Manager's Project Map in figure 10 has well self-explained this purpose. The project manager Jin led the project to success by influencing project management process, project outcomes, and contextual factors. The project success in this case includes the contribution to the consolidation of two state universities and maximization of library resources for the organization. The outcomes of the merger project are to deliver a consolidated ILS and to provide library services for the new university continuously. Figure 10 clearly indicates Jin managed business continuity and project deliverables 
through downtime and load acceptance. Among contextual factors, the project manager executed project involvement through engaging system users and vendors and gathering user feedback. She also involved top management David in the project directly. Senior management empowered Jin to make decisions on the project. As a manager her qualifications enabled her to cope with the complexity of the project. The project documentation has verified the manager's ability to govern the project. For instance, figure 11 is the project framework that the manager created according to the PMBOK (Project Management Body of Knowledge). Hence, a qualified project manager can directly make impacts on project success through contextual factors.

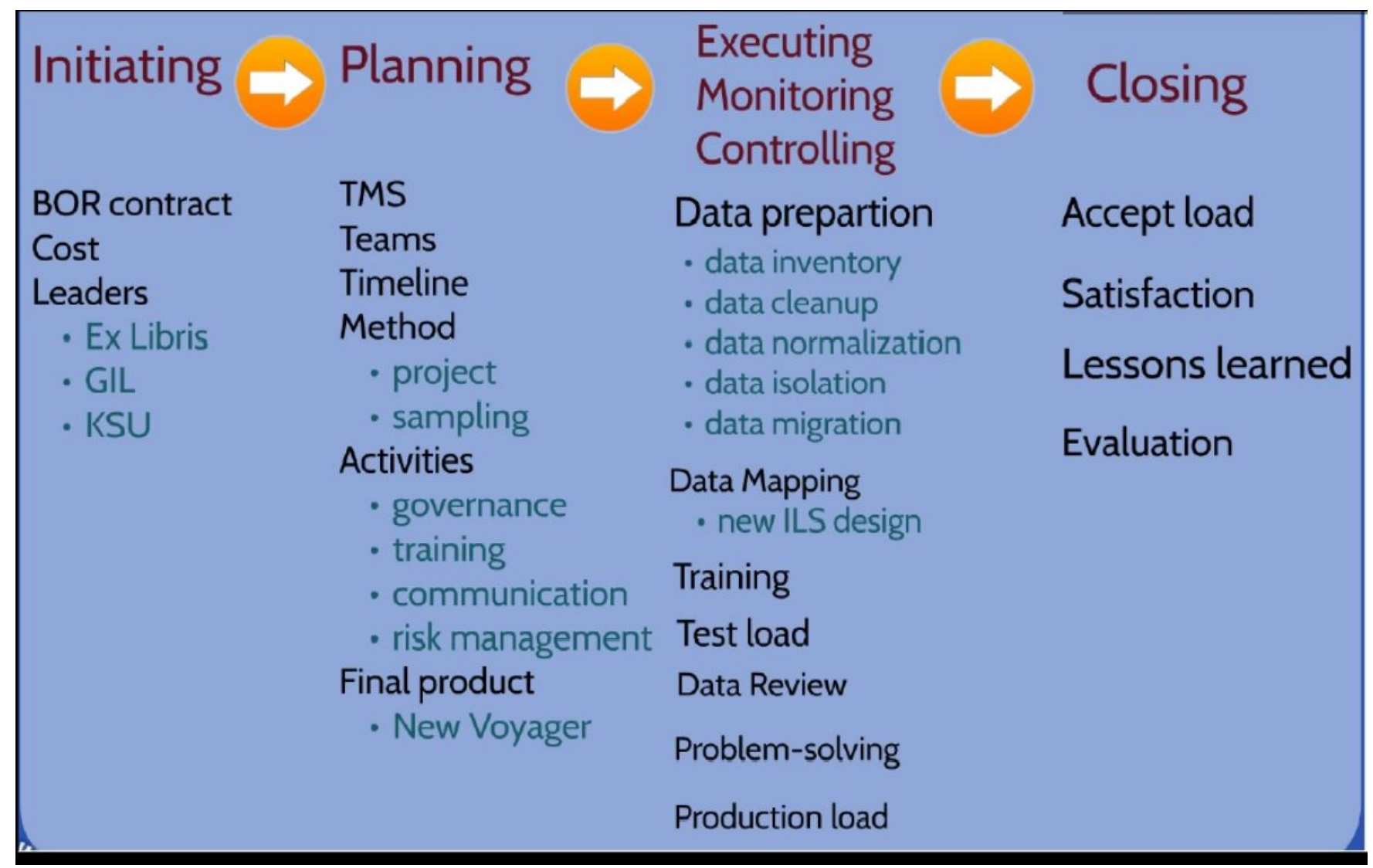

Figure 11. KSU Library ILS Merger Project Management Framework.

Meanwhile, the nodes of barcode, mappings, missing, patrons, and vendors confirm the manager's role in project quality control. The coding of the deadline, cost-consolidation, communication, and risk control indicates the manager put her effort in project time, cost, and communication management and risk mitigation correspondingly.

Figure 10 reveals the project manager is the core of the project team and makes significant impacts on project success by influencing project management process, contextual factors and project outcomes. A project manager must fully understand project outputs; have the ability to execute project plans in the business environment, and communicate with different stakeholders at the corresponding levels through various channels since communication becomes challenging when a project involves more people from different sections of the business. People decode messages differently. Multiple communication chains can help stakeholders gain consistent and accurate information directly. For example, this project manager utilized formal reports, group 
discussions, training, and weekly coordination meetings to share information and seek feedback. The functional groups are the governance structure of the project. In the phrase of test and production loads, the leaders of functional groups communicated problems with the project manager more frequently to ensure the manager resolve issues in collaboration with related stakeholders (e.g. Ex Libris) in a timely way. In the meantime, the project manager communicated the expectations for responsible IT staff regularly to prevent the additional waiting time for feeding the merged ILS with patron data by verifying the feeder during the test load, which helps meet the deadlines of the campus IT projects. The manager mitigated risk by implementing the project plan thoughtfully throughout the project. It was the project manager who connects the three variables - project management process, project outcomes, and contextual factors with project success.

\section{CONCLUSIONS}

Libraries have used the ILS to manage resources and services for decades. With the exponential growth of digital information, IS innovation continuously becomes one of most effective drivers of library transformation. Therefore, it is crucial for libraries to effectively manage IS/IT projects to achieve organizational goals. This study develops a model of IS project success. The model employs three constructs namely project management process, project outcomes, and contextual factors to measure IS project success. Project management success cannot bring IS project success unless the project results achieve business goals and lead to the improvement of organizational effectiveness. The project manager makes important impacts on project success by delivering project outcomes through implementing project management process and making use of contextual factors throughout the project. The research methodology-software-assisted qualitative content analysis can be an approach to develop or test a theoretical model for library practitioners. A post-project evaluation can create an excellent opportunity for organizational learning and help managers to manage talents better and improve the chances of project success in the future.

\section{FUTURE RESEARCH}

Libraries have moved into a new era that is full of new and disruptive technologies, which affect library services, operations, and decisions on a daily basis. IS projects will continue bringing innovations to library services and programs. A theoretical framework could provide librarians a methodology to manage IS projects successfully. Notably, the U.S. Senate has unanimously approved the Program Management Improvement and Accountability Act (PMIAA) to enhance project and program management practices to maximize efficiency in the federal government. ${ }^{23}$ Project management has become a must-have skill for today's library leaders.

There are many opportunities for managers to test the IS project success model through their practices. The future studies may combine quantitative and qualitative methods to assess and enhance the model further. Each institution has different goals and contextual indicators that the author has not mentioned in this study. These factors might shift from minor to major or vice versa due to different organizational cultures. Practitioners can also use NVivo to collaborate on double coding to increase the analytical reliability. A software-assisted qualitative content analysis will help library leaders to understand project management better and experiment the solutions to complex information world. 


\section{ACKNOWLEDGEMENTS}

This work would not have been possible without the support of the KSU Library System Administration and the team efforts from KSU Voyager Consolidation Committee, GIL Support, and Ex Libris Team. I am grateful to all of those with whom I have had the privilege to work during this project.

\section{REFERENCES}

${ }^{1}$ John Nicholas and Gezinus Hidding, "Management Principles Associated with IT Project Success," International Journal of Management and Information Systems 14, no. 5 (Nov. 2, 2010): 147-56, https://doi.org/10.19030/ijmis.v14i5.22.

${ }^{2}$ Alan R. Peslak, "Information Technology Project Management and Project Success," International Journal of Information Technology Project Management 3, no. 3 (July 2012): 31-44, https://doi.org/10.4018/jitpm.2012070103.

${ }^{3}$ Udechukwu Ojiako, Eric Johansen, and David Greenwood, “A Qualitative Re-construction of Project Measurement Criteria.” Industrial Management \& Data Systems 108, no. 3 (Mar. 2008): 405-17, https://doi.org/10.1108/02635570810858796.

${ }^{4}$ Claudia-Georgeta Cảrstea, "IT Project Management-Cost, Time and Quality," Economy Transdisciplinarity Cognition 17, no. 1 (Mar. 2014): 28-34, http://www.ugb.ro/etc/etc2014no1/07 Carstea C..pdf.

${ }^{5}$ Wen-Hsien Tsai et al., "An Empirical Investigation of the Impacts of Internal/External Facilitators on the Project Success of ERP: A Structural Equation Model," Decision Support Systems 50, no. 2 (Jan. 2011): 480-90, https://doi.org/10.1016/j.dss.2010.11.005.

${ }^{6}$ Raymond Young and Ernest Jordan, “Top Management Support: Mantra or Necessity?" International Journal of Project Management 26, no. 7 (Oct. 2008): 713-25, https://doi.org/10.1016/j.ijproman.2008.06.001.

${ }^{7}$ Z. Irani, "Investment Evaluation within Project Management: An Information Systems Perspective," The Journal of the Operational Research Society 61, no. 6 (June 2010): 917-28, https://doi.org/10.1057/jors.2010.10.

${ }^{8}$ Peslak, "Information Technology Project Management and Project Success," 31-44.

${ }^{9}$ Tadeau Oliveira de Lacerda, Leonardo Ensslin, and Sandra Rolim Ensslin, "A Performance Measurement View of IT Project Management," International Journal of Productivity and Performance Management 60, no. 2 (2011): 132-51, https://doi.org/10.1108/17410401111101476.

${ }^{10}$ Nicholas and Hidding, “Management Principles,” 153.

${ }^{11}$ Graeme Thomas and Walter Fernández, "Success in IT Projects: A Matter of Definition?" International Journal of Project Management 26, no. 7 (Oct. 2008): 733-42, https://doi.org/10.1016/j.ijproman.2008.06.003. 
${ }^{12}$ Elmar Kutsch, "The Measurement of Performance in IT Projects," International Journal of Electronic Business 5, no. 4 (2007): 415, https://doi.org/10.1504/IJEB.2007.014786.

${ }^{13}$ Joana G. Geraldi, Elmar Kutsch, and Neil Turner, "Towards a Conceptualisation of Quality in Information Technology Projects," International Journal of Project Management 29, no. 5 (July 2011): 557-67, https://doi.org/10.1016/i.ijproman.2010.06.004.

${ }^{14}$ Ryan S. Hoover and Amy L. Koerber, "Using NVivo to Answer the Challenges of Qualitative Research in Professional Communication: Benefits and Best Practices Tutorial," IEEE Transactions on Professional Communication 54, no. 1 (Mar. 2011): 68-82, https://doi.org/10.1109/TPC.2009.2036896.

${ }^{15}$ Erika Goble et al., "Habits of Mind and the Split-Mind Effect: When Computer-Assisted Qualitative Data Analysis Software is used in Phenomenological Research," Forum: Qualitative Social Research 13, no. 2 (May 2012): 1-22, https://doi.org/10.17169/fqs-13.2.1709.

${ }^{16}$ Peter Balan et al., "Concept Mapping as a Methodical and Transparent Data Analysis Process," in Handbook of Qualitative Organizational Research (London: Routledge, 2015): 318-30, https://doi.org/10.4324/9781315849072.

${ }^{17}$ Syed Zubair Haider and Muhammad Dilshad, "Higher Education and Global Development: A Cross Cultural Qualitative Study in Pakistan," Higher Education for the Future 2, no. 2 (July 2015): 175-93, https://doi.org/10.1177/2347631114558185.

${ }^{18}$ Andrew John Hutchison, Lynne Halley Johnston, and Jeff David Breckon, "Using QSR-NVivo to Facilitate the Development of a Grounded Theory Project: An Account of a Worked Example," International Journal of Social Research Methodology 13, no. 4 (Oct. 2010): 283-302, https://doi.org/10.1080/13645570902996301.

${ }^{19}$ Florian Kaefer, Juliet Roper, and Paresha Sinha. "A Software-Assisted Qualitative Content Analysis of News Articles: Example and Reflections," Forum: Qualitative Social Research 16, no. 2 (May 2015): 1-20, https://doi.org/10.17169/fqs-16.2.2123.

${ }^{20}$ Trena Paulus et al., "The Discourse of QDAS: Reporting Practices of ATLAS.Ti and NVivo Users with Implications for Best Practices," International Journal of Social Research Methodology 20, no. 1 (Jan. 2017): 35-47, https://doi.org/10.1080/13645579.2015.1102454.

21“About Coding," NVivo Help (Melbourne, Australia: QSR International, 2018), accessed Apr. 3 2018, http://helpnv11.qsrinternational.com/desktop/concepts/about coding.htm?rhsearch=coding\&rhsyns=.

${ }^{22}$ Paulus et al., "Discourse of QDAS," 41.

23 “U.S. Senate Unanimously Approves the Program Management Improvement and Accountability Act," Business Wire (Dec. 2016) accessed Nov. 10, 2017, http://www.businesswire.com/news/home/20161201006499/en/U.S.-Senate-UnanimouslyApproves-Program-Management-Improvement. 